\title{
Clostridium difficile infection in medical wards - a mathematical model
}

\author{
V Schechner ${ }^{1 *}$, Y Carmeli ${ }^{1}$, M Leshno $^{2}$ \\ From 3rd International Conference on Prevention and Infection Control (ICPIC 2015) \\ Geneva, Switzerland. 16-19 June 2015
}

\section{Introduction}

Clostridium difficile infection (CDI) is a common and potentially fatal healthcare-associated infection. Better isolation of CDI patients may prevent transmission and reduce $\mathrm{CDI}$ cases.

\section{Objectives}

To determine 1) the dynamics of CDI, and 2) the association between CDI transmission and prevalence of CDI, among hospitalized patients in internal medicine wards.

\section{Methods}

Daily reports were created retrospectively to obtain the number of hospitalized CDI patients per day in the 350 beds internal medicine department for 3 years (March 2010 to February 2013); data were evaluated for stationarity and autocorrelation. A mathematical model of CDI transmission was constructed based on hospital data. The model consisted of three compartments: susceptible patients, asymptomatic carriers and CDI patients. We used the model results to assess the transmission rate from infected patients under different infection control scenarios.

\section{Results}

The number of CDI patients in the internal medicine department is stationary; the autocorrelation function of this parameter is high (i.e., 90\%) for a lag time of 1 day and it decreases gradually thereafter (i.e., $56 \%$ for a lag of 7 days, and $44 \%$ for a lag of 14 days). The average number of CDI cases increases exponentially as the transmission rate increases; a major reduction in the number of CDI patients (from 18.0 to 8.5 patients per 350 beds) can be achieved by modestly lowering the transmission rate

${ }^{1}$ Tel Aviv Sourasky Medical Center, Tel Aviv, Israel

Full list of author information is available at the end of the article through contact isolation precautions, but further reduction in the average number of infected cases requires more substantial changes in the transmission rate. The basic reproduction rate during the study period, as derived from the model results, was calculated as 1.09 indicating endemicity

\section{Conclusion}

Hospitals should be encouraged to improve patient isolation in order to reduce CDI cases.

\section{Disclosure of interest}

None declared.

\section{Authors' details}

${ }^{1}$ Tel Aviv Sourasky Medical Center, Tel Aviv, Israel. ${ }^{2}$ Tel Aviv University, Tel Aviv, Israel.

Published: 16 June 2015

doi:10.1186/2047-2994-4-S1-034

Cite this article as: Schechner et al:: Clostridium difficile infection in medical wards - a mathematical model. Antimicrobial Resistance and Infection Control 2015 4(Suppl 1):O34.

Submit your next manuscript to BioMed Central and take full advantage of:

- Convenient online submission

- Thorough peer review

- No space constraints or color figure charges

- Immediate publication on acceptance

- Inclusion in PubMed, CAS, Scopus and Google Scholar

- Research which is freely available for redistribution 